\title{
Past and Current Perspectives in Modeling Bacteria and Blood-Brain Barrier Interactions
}

\author{
Brandon J. Kim ${ }^{1}$, Eric V. Shusta ${ }^{2}$ and Kelly S. Doran ${ }^{3 *}$ \\ ${ }^{1}$ Institute for Hygiene and Microbiology, University of Würzburg, Würzburg, Germany, ${ }^{2}$ Department of Chemical \\ and Biological Engineering, University of Wisconsin, Madison, WI, United States, ${ }^{3}$ Department of Immunology \\ and Microbiology, University of Colorado School of Medicine, Aurora, CO, United States
}

\section{OPEN ACCESS}

Edited by:

Juan Pablo Olano,

The University of Texas Medical Branch at Galveston, United States

Reviewed by:

Paul Dean,

Teesside University, United Kingdom Maren Von Köckritz-Blickwede,

University of Veterinary Medicine Hanover, Germany Mohd Nasir Mohd Desa, Putra Malaysia University, Malaysia

${ }^{*}$ Correspondence: Kelly S. Doran

Kelly.doran@ucdenver.edu

Specialty section: This article was submitted to Infectious Diseases,

a section of the journal Frontiers in Microbiology

Received: 28 January 2019 Accepted: 29 May 2019

Published: 13 June 2019

Citation:

Kim BJ, Shusta EV and Doran KS (2019) Past and Current Perspectives in Modeling Bacteria and Blood-Brain

Barrier Interactions.

Front. Microbiol. 10:1336. doi: 10.3389/fmich.2019.01336
The central nervous system (CNS) barriers are highly specialized cellular barriers that promote brain homeostasis while restricting pathogen and toxin entry. The primary cellular constituent regulating pathogen entry in most of these brain barriers is the brain endothelial cell (BEC) that exhibits properties that allow for tight regulation of CNS entry. Bacterial meningoencephalitis is a serious infection of the CNS and occurs when bacteria can cross specialized brain barriers and cause inflammation. Models have been developed to understand the bacterial - BEC interaction that lead to pathogen crossing into the CNS, however, these have been met with challenges due to these highly specialized BEC phenotypes. This perspective provides a brief overview and outlook of the in vivo and in vitro models currently being used to study bacterial brain penetration, and opinion on improved models for the future.

Keywords: bacteria, blood-brain barrier, meningitis, stem cells, brain endothelial cell

\section{THE BRAIN BARRIERS}

The brain barriers are comprised of a number of endothelial and epithelial cellular barriers that serve to maintain brain homeostasis and prevent pathogen entry into the central nervous system (CNS; Engelhardt and Sorokin, 2009; Abbott et al., 2010; Redzic, 2011). These barriers are especially adept at regulating nutrients and molecules passage into the CNS, while at the same time restricting access to many xenobiotic drugs and pathogens (Engelhardt and Sorokin, 2009; Abbott et al., 2010; Redzic, 2011; Spindler and Hsu, 2012; Doran et al., 2016). In the average adult human, the total cerebral microvasculature has been estimated at a total surface area of $15-25 \mathrm{~m}^{2}$, and a total length of around $600 \mathrm{~km}$ (Zlokovic, 2005; Wong et al., 2013). The endothelial blood-brain barrier (BBB) makes up the majority of the brain microvasculature and is the primary location for exchange processes between the circulation and CNS (Redzic, 2011). The BBB is supported by a number of other cell types, such as astrocytes, pericytes, and neurons [collectively called the neurovascular unit (NVU)], that not only enhance barrier properties, but also regulate the ability of the endothelial cell to transport essential nutrients into the CNS and discharge metabolic products from the CNS into the blood (Abbott et al., 2010). The endothelium of the BBB possesses barrier properties different than other vascular networks elsewhere in the body, and these phenotypes contribute to their ability to function. The meningeal blood-cerebral spinal fluid barrier (mBCSFB) is an additional endothelial barrier comprised of brain vessels with similar properties to the BBB, although not supported by the NVU and associated cell types. Instead, the endothelium of the mBCSFB is surrounded by cerebral spinal fluid (CSF), and can be closely associated with leptomeningeal cells 
(Rua and McGavern, 2018). An important epithelial brain barrier can be found in the choroid plexus (CP) where the capillaries are more similar to those of the peripheral endothelium exhibiting fenestrations and do not form a barrier, instead a single layer of specialized epithelial cells forms the barrier phenotype of the CP. These epithelial cells are the principle component of what is known as the blood-CSF barrier (BCSFB; Engelhardt and Sorokin, 2009). One of the major phenotypes that describe each of these brain barriers is the presence of tight junctions that seal adjacent cells to one another, and represent a distinctive barrier phenotype of the brain barriers (Engelhardt and Sorokin, 2009). The tight junctions are formed by a host of transmembrane proteins including occludin, ZO-1 and claudin-5 (Nitta et al., 2003). To cause serious CNS infection, infectious agents such as bacteria, viruses, and parasites, must cross or subvert these brain barriers.

Bacterial meningoencephalitis is a serious infection of the CNS and is uniformly fatal if left untreated. Certain bacteria that cause meningoencephalitis have the ability to interact with and penetrate one or more of the brain barriers allowing access to the CNS and causing inflammation. This perspective outlines models utilized to examine bacterial pathogen-brain barrier studies, and discusses the incorporation of novel barrier models with particular focus on the endothelial barriers of the CNS and the key bacterial pathogens associated with meningoencephalitis and CNS disease.

\section{BACTERIAL PATHOGENS ASSOCIATED WITH CNS DISEASE}

There are a number of bacterial pathogens capable of interacting with and penetrating brain endothelial cells (BECs) to gain access to the CNS and cause meningoencephalitis. Neisseria meningitidis (meningococcus) and Streptococcus pneumoniae (pneumococcus) are leading causes of meningoencephalitis in young adults and the elderly (Doran et al., 2016; Coureuil et al., 2017). N. meningitidis is a leading cause of epidemic meningococcal meningoencephalitis in the "meningitis belt" of sub-Saharan Africa and developing nations, but remains a health threat in the developed world (Doran et al., 2016; SchubertUnkmeir, 2017). Streptococcus pneumonaie (pneumococcus) remains a common cause of bacterial meningoencephalitis despite the development of multivalent vaccines (Feikin et al., 2013; Doran et al., 2016). Meningeal pathogens that affect the newborn include Streptococcus agalactiae, commonly known as Group B Streptococcus (GBS), and Escherichia coli K1. GBS is the leading cause of neonatal meningoencephalitis and can be vertically transmitted from mother to newborn during the birthing process (Doran and Nizet, 2004). While prophylactic antibiotic treatment has limited maternal GBS colonization and transmission to the newborn, treatment has had little impact on the incidence of GBS meningoencephalitis (Berardi et al., 2013). E. coli K1 is the second leading cause of neonatal meningoencephalitis. While modern antibiotic treatments have reduced mortality, complications remain due to the amount of endotoxin that remains from dead bacteria resulting in septic shock (Shenep and Mogan, 1984; Doran et al., 2016). Some additional bacterial pathogens may under specific conditions or in certain hosts cause CNS disease, such as Listeria monocytogenes, Mycobacterium tuberculosis, Streptococcus suis, Salmonella spp., Klebsiella spp., and Staphylococcus aureus. In general, many of these pathogens can persist in the human as a normal colonizer of mucosal surfaces. However, in certain cases can enter the blood stream, replicate to high levels, and interact with brain barriers where they may gain access to the CNS (Doran et al., 2016). Presently various models to understand how these pathogens enter the CNS have been employed and better appropriations of cellular brain barriers are being developed.

\section{IN VIVO MODELS USED TO STUDY BRAIN PENETRATION AND CNS DISEASE}

To elucidate mechanisms of penetration of the BBB by pathogens in the context of live organisms, researchers utilize in vivo models of CNS transit and pathology. These models have the advantage of possessing intact brain barriers, and are conducted in the context of a competent immune system. Much work has been done to elucidate mechanisms of BBB dysfunction during infection using mouse, rat, rabbit, and zebrafish models, and each model has distinct advantages and disadvantages. Identifying in vivo mechanisms of brain barrier traversal is a critical step in understanding the pathogenesis of many meningeal pathogens.

Rodent models have been widely utilized to study bacterial meningoencephalitis, specifically the mouse and rat. Typically, these models can be distinguished mainly by the route of injection. Direct infection of the CNS through intra-cerebral or intra-cisternal route allows for the monitoring of hostpathogen interactions once the pathogen is in the CNS as well as leukocyte transmigration (Shapiro et al., 2000; Koedel et al., 2001; Grandgirard et al., 2007; Reiß et al., 2011; Koopmans et al., 2018). While this method is useful, it lacks a more natural course of dissemination through the blood stream (Chiavolini et al., 2008). To this end, hematogenous routes have been employed introducing bacteria via intraperitoneal, intravenous, or intracardiac injections. This route allows for the development of bacteriemia prior to crossing of the brain barriers and better models a blood to CNS transit of bacteria (Ferrieri et al., 1980; Kim et al., 1992, 2015a; Tan et al., 1995; Hoffman et al., 2000; Wang and Kim, 2002; Liu et al., 2004; Doran et al., 2005; Banerjee et al., 2010). Alternate routes of infection leading to meningoencephalitis have been utilized such as intranasal administration of bacteria (Ferrieri et al., 1980; Zwijnenburg et al., 2001; Mittal et al., 2010, 2011). This method can be especially useful when examining a pathogen that typically colonizes the nasopharynx and surrounding tissue such as with S. pneumoniae (Zwijnenburg et al., 2001). In the case of food-borne pathogens, such as L. monocytogenes, intragastric infection can be useful to mimic disease (Lecuit et al., 2001; 
Maury et al., 2016). Recently, an interesting mouse model for GBS infection was employed that relied on a colonized mother passing along GBS to neonates vertically as it is hypothesized to take place in human infection (Andrade et al., 2018). While extremely useful and widely used, rodent models have their limitations especially when it comes to pathogens such as L. monocytogenes and N. meningitidis which are primarily human specific pathogens. In order to model disease with these pathogens, transgenic mice which express specific human genes or humanized mice are often utilized which limits the scope of the interactions that may be studied (Mackinnon et al., 1992; Lecuit et al., 2001; Yi et al., 2003; Zarantonelli et al., 2007; Johswich et al., 2013; D’Orazio, 2014; Maury et al., 2016).

In addition to rodent models, other in vivo systems have been developed to study bacterial penetration of brain barriers and progression of meningoencephalitis. The zebrafish (Danio rerio) has certain advantages such as high group numbers, optically clear, and genetically tractable. In recent years zebrafish have been used to model brain barrier crossing or meningoencephalitis for Mycobacterium, GBS, S. pneumoniae, and Streptococcus iniae (Patterson et al., 2012; Harvie et al., 2013; van Leeuwen et al., 2014; Kim et al., 2015a,b; Jim et al., 2016). Interestingly pathogens like $S$. iniae and GBS are zoonotic pathogens impacting fish in aquaculture with pathology similar to humans, as it can cause meningoencephalitis in fish (Delannoy et al., 2013; Wang et al., 2017; Mishra et al., 2018). Thus, the zebrafish model presents an interesting method to examine bacterial pathogenesis in fish as well to improve aquaculture methods. However, it is important to note that the zebrafish $\mathrm{BBB}$ differs from the mammalian $\mathrm{BBB}$ particularly due to the lack of true astrocytes, instead they possess a different glial cell type that serves a similar purpose (O'Brown et al., 2018). Other less common mammalian models include the rabbit, guinea pig, and the gerbil to model meningoencephalitis in a wide range of pathogens (Michael Scheld et al., 1979; Sinai et al., 1980; Sulc et al., 1992; Zysk et al., 1996; Blanot et al., 1997; Tauber, 1998; Marra and Brigham, 2001; Chiavolini et al., 2008; D’Orazio, 2014; Tucker et al., 2016). In certain cases, non-human primates have been used and demonstrate natural meningoencephalitis, especially with L. monocytogenes (Kaufmann and Quist, 1969; Mook-kanamori et al., 2011; Lemoy et al., 2012; Scanga and Flynn, 2014). However, these models are often cost and facilities-prohibitive and difficult to get approved due to institutional restrictions. Each in vivo model offers specific advantages and/or disadvantages and selection of models may come down to availability and usefulness to the research question.

\section{THE USE OF IN VITRO MODELS OF ENDOTHELIAL BRAIN BARRIERS DURING INFECTION}

In vitro models comprised of human BECs eliminate some of the pitfalls from the in vivo models such as interspecies

TABLE 1 | Comparison of in vitro BEC models.

\begin{tabular}{|c|c|c|c|c|c|c|}
\hline Model & Type & $\begin{array}{c}\text { TEER } \\
\left(\Omega \times \mathrm{cm}^{2}\right)\end{array}$ & Tight junctions & $\begin{array}{l}\text { Bacterial pathogens } \\
\text { studied }\end{array}$ & $\begin{array}{l}\text { Model origin } \\
\quad \text { (year) }\end{array}$ & References \\
\hline hBMEC & $\begin{array}{l}\text { Human immortalized by } \\
\text { SV40 large T antigen }\end{array}$ & 20 to 40 & $\begin{array}{l}\text { ZO-1 and Occludin } \\
\text { present. Claudin-5 } \\
\text { absent }\end{array}$ & $\begin{array}{l}\text { S. pneumoniae, } \\
\text { S. agalactiae, E. coli Kl, } \\
\text { L. monocytogenes, } \\
\text { N. meningitidis, B. abortus, } \\
\text { C. freundii, and others }\end{array}$ & 1997 & $\begin{array}{l}\text { Badger et al., 1999; } \\
\text { Banerjee et al., 2010; } \\
\text { Doran et al., 2005; } \\
\text { Eigenmann et al., 2013; } \\
\text { Greiffenberg et al., } \\
\text { 1998; Helms et al., } \\
\text { 2015; Hoffman et al., } \\
\text { 2000; Badger et al., } \\
\text { 2002; Miraglia et al., } \\
\text { 2018; Nizet et al., } \\
\text { 1997; Stins et al., 2001; } \\
\text { Uchiyama et al., 2009 }\end{array}$ \\
\hline hCMEC/D3 & $\begin{array}{l}\text { Human immortalized by } \\
\text { SV40 large T antigen } \\
\text { and hTERT }\end{array}$ & 10 to 200 & $\begin{array}{l}\text { ZO-1, Occludin, and } \\
\text { Claudin-5 present }\end{array}$ & $\begin{array}{l}\text { N. meningitidis, } \\
\text { S. agalactiae, } \\
\text { S. pneumoniae, S. suis }\end{array}$ & 2005 & $\begin{array}{l}\text { Bernard et al., 2014; } \\
\text { Coureuil et al., 2010; } \\
\text { Deng et al., 2018; } \\
\text { Eigenmann et al., 2013; } \\
\text { Helms et al., 2015; } \\
\text { Jiménez-Munguía et al., } \\
\text { 2018; Wang et al., } \\
\text { 2015; Weksler et al., } \\
2005\end{array}$ \\
\hline $\begin{array}{l}\text { iPSC-derived } \\
\text { BECs }\end{array}$ & $\begin{array}{l}\text { Human stem-cell } \\
\text { derived }\end{array}$ & 250 to $5000+$ & $\begin{array}{l}\text { ZO-1, Occludin, and } \\
\text { Claudin-5 present and } \\
\text { localized to cell-cell } \\
\text { junctions }\end{array}$ & $\begin{array}{l}\text { S. agalactiae, } \\
\text { N. meningitidis }\end{array}$ & 2012 & $\begin{array}{l}\text { Gomes et al., 2019; } \\
\text { Helms et al., 2015; } \\
\text { Hollmann et al., 2017; } \\
\text { Kim et al., 2017; } \\
\text { Lippmann et al., 2012, } \\
\text { 2014; Qian et al., 2017; } \\
\text { Stebbins et al., 2016 }\end{array}$ \\
\hline
\end{tabular}


A Stem cell derived brain endothelial cell differentiation process.

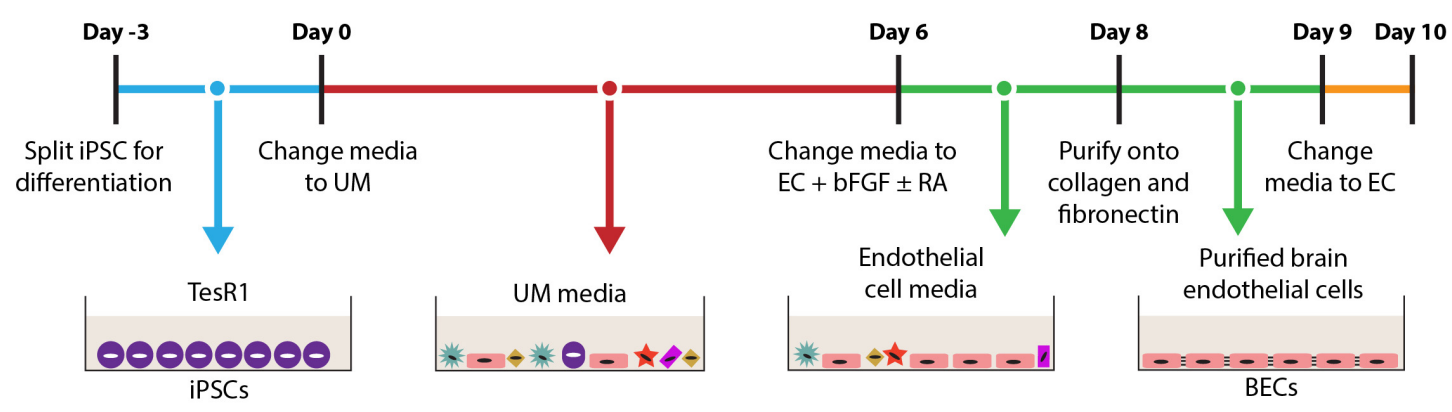

B Group B Streptococcus interaction with stem cell derived brain endothelial cells.

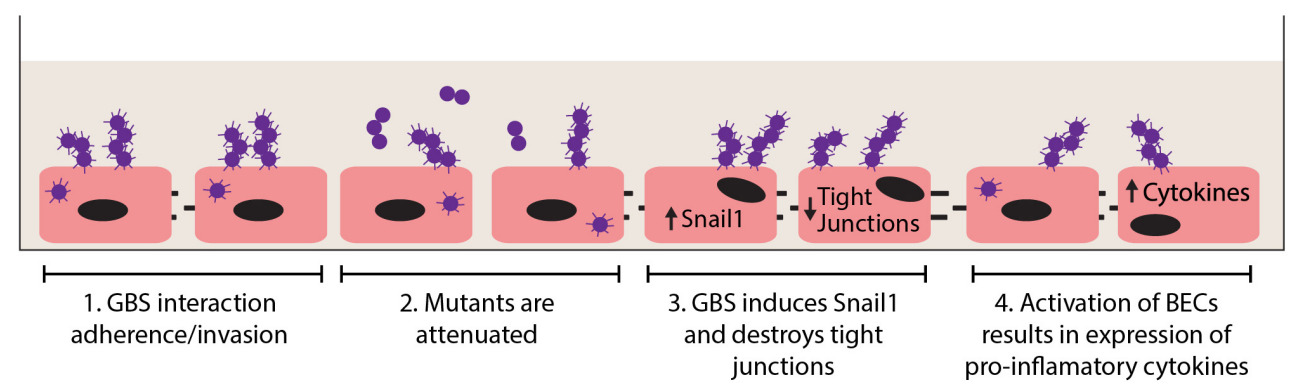

C Potential co-culture geometry using various cell types.

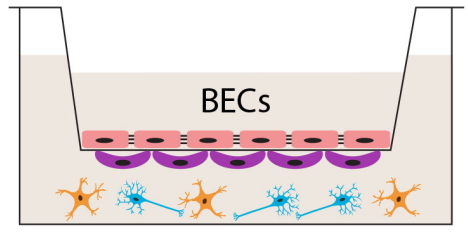

Astrocytes, Pericytes, and Neurons

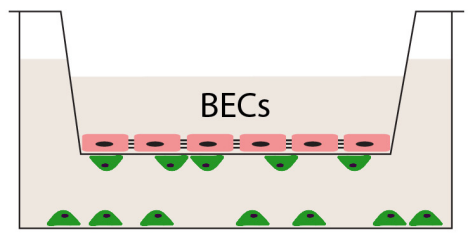

Leptomeningeal cells

FIGURE 1 | Schematic diagrams of iPSC-derived BEC models and co-culture. (A) Derivation of iPSC-derived BECs adapted from Lippmann et al. (2012). Overall the 13-day process results in purified iPSC-derived BECs. Day-3 to 0 iPSCs are expanded in TesR1 media. Day 0-6, cells are differentiated in unconditioned media (UM). Days 6-9, endothelial cells are expanded using endothelial cell (EC) media supplemented with basic fibroblast growth factor (bFGF), and retinoic acid (RA). On day 8 endothelial cells are purified onto a collagen/fibronectin matrix. Day 9 cells get a final change into EC media. (B) Schematic GBS infection of iPSC-BECs as described in Kim et al. (2017). B1, demonstrated that GBS can interact with iPSC-BECs by adherence, invasion, and intracellular survival. B2, GBS mutants are attenuated for iPSC-BEC interaction. B3, GBS induces the tight junction repressor Snail1 previously shown to contribute to the destruction of tight junctions. B4, innate immune activation is seen through the upregulation of cytokines and chemokines. (C) Potential transwell model combinations in co-culture with iPSC-derived BECs with other cell types of the CNS such as astrocytes (orange), neurons (blue), pericytes (purple), and leptomeningeal cells (green).

differences, scalability, and availability (Syvänen et al., 2009; Warren et al., 2009; Lippmann et al., 2012). One of the first immortalized cell lines utilized for study of bacterial BEC interaction was the human brain microvascular endothelial cell (hBMEC) line. Cells were initially isolated from a patient with epilepsy and then immortalized by the transformation with SV40 large T-antigen (Nizet et al., 1997). The hBMEC line has been used widely for the determination of bacterial-BEC interactions with bacterial pathogens such as S. pneumoniae, GBS, N. meningitidis, E. coli K1, L. monocytogenes, and others (Nizet et al., 1997; Greiffenberg et al., 1998; Badger et al., 1999, 2002; Hoffman et al., 2000; Stins et al., 2001; Doran et al., 2005; Uchiyama et al., 2009; Banerjee et al., 2010;
Miraglia et al., 2018). While this model has been used successfully over the years for mechanistic studies, it has some limitations including the lack of certain BEC key characteristics such as continuous tight junction staining and claudin-5 expression (Table 1; Kim et al., 2017). Other immortalized BECs such as hCMEC/D3 have been developed by transforming microvessels isolated from an epileptic patient, with hTERT and SV40 (Weksler et al., 2005). This model has been employed to examine interactions with various infectious agents ranging from bacteria, viruses, fungi, and parasites (Coureuil et al., 2010; Bernard et al., 2014; N’Dilimabaka et al., 2014; Volle et al., 2015; Wang et al., 2015; Mutso et al., 2017; Aaron et al., 2018; Deng et al., 2018; Jiménez-Munguía et al., 2018). 
The hCMEC/D3 model better recapitulates more phenotypes of BECs, such as claudin-5 expression, however, they still do not localize certain tight junction components and produce relatively low transendothelial electrical resistance (TEER), indicative of suboptimal barrier function (Weksler, 2005; Eigenmann et al., 2013). Each in vitro model using primary or immortalized BECs has differing attributes that must be carefully assessed depending on envisioned application, and a comprehensive review can be found elsewhere (Helms et al., 2015).

\section{IMPROVED IN VITRO MODELS AND FUTURE OUTLOOKS}

As mentioned above, many of the primary and immortalized BBB models lack critical BEC phenotypes limiting their usefulness (Helms et al., 2015). This highlights the challenge of modeling human BECs in vitro, as many of the models may lack key BBB properties. Primary cells may have low availability and once removed from the brain microenvironment, lose phenotypes associated with BECs (Lippmann et al., 2012; Helms et al., 2015). Additionally while immortalized BECs are highly scalable, they only offer a facile model and often lack continuous tight junctions and appropriate barrier function (Table 1; Lippmann et al., 2013; Helms et al., 2015; Rahman et al., 2016). In our opinion, recent advances in stem cell-based technologies offer the prospects of superior BBB modeling. These human stem cell-derived BECs possess expected markers, functional transporters, and continuous tight junction staining corresponding to the high TEER values (Table 1; Lippmann et al., 2012, 2014; Cecchelli et al., 2014; Stebbins et al., 2016; Hollmann et al., 2017; Qian et al., 2017). Using human induced pluripotent stem cells (iPSCs), BECs can be generated without the requirement of co-culture with other NVU cell types, and iPSC sources offer the added benefit of being easily scalable (Lippmann et al., 2012, 2014). Figure 1A provides an example of one differentiation process to achieve BECs from iPSC sources that has been utilized (Lippmann et al., 2012, 2014). The iPSC model has been used to examine drug delivery, genetic human disease and ischemic stroke (Clark et al., 2016; Vatine et al., 2016; Kokubu et al., 2017; Lim et al., 2017), but only recently has it been evaluated for the study of microbe interactions. It was shown that GBS adhere to, invade, and activate the iPSC-derived BECs, while GBS mutants known to have diminished $\mathrm{BBB}$ interaction were attenuated in the iPSC-derived model (Figure 1B; Kim et al., 2017). GBS infection also resulted in the disruption of tight junction components, ZO-1, Occludin, and Claudin-5 (Figure 1B). Furthermore, it was shown that a mechanism of GBS destruction of tight junctions through the Snaill transcription factor was consistent in the iPSC-BEC model (Kim et al., 2017). While this mechanism was first shown using GBS, recently another meningeal pathogen, E. coli $\mathrm{K} 1$, has been found to induce Snail1 (Kim et al., 2015a; Yang et al., 2016). We anticipate that this mechanism of tight junction disruption may be utilized by other pathogens, and the iPSC-BEC model, with superior tight junction and barrier function would be an ideal system for conducting these studies. This demonstrates that the iPSC-derived BBB model can be utilized to study BBB interaction with bacterial CNS pathogens, and has the potential to be expanded to other pathogens. Interestingly, researchers have used iPSC-derived BECs to demonstrate that Zika virus can cross BECs without disrupting the junctions (Alimonti et al., 2018). A recent proof of principle publication showed that iPSC-BECs can also model interactions with the human specific N. meningitidis (Gomes et al., 2019). Thus, human iPSC-derived BEC models hold promise for further study of human specific pathogens, particularly those that lack robust in vivo models.

Advances in biological engineering have also paved the way for the modeling of other aspects of the brain barriers such as shear stress to mimic blood flow, and co-culture with supporting cell types of the NVU (e.g., astrocytes, pericytes, and leptomeningeal cells). BECs respond to cues from NVU by enhancing $\mathrm{BBB}$ phenotypes such as TEER, and tight junctions. Co-culture models have utilized the Transwell system and demonstrated enhanced properties with stem cell derived ECs and BECs. (Lippmann et al., 2012; Cecchelli et al., 2014; Appelt-Menzel et al., 2017; Canfield et al., 2017). It would thus be possible to model bacterial interaction during coculture with enhanced $\mathrm{BBB}$ properties and potential cross talk between cells (Figure 1C). Direct interactions with glial cell types such as astrocytes and microglia have been explored, and in general it appears that glial cells respond by secreting cytokines and chemokines (Cooley et al., 2014; Stoner et al., 2015; Seele et al., 2016). Additionally, interactions at the mBCSFB would occur between bacteria and BECs that are supported by leptomeningeal cells, nevertheless until now only direct interactions with a cancerous leptomeningeal cell line have been investigated (Fowler et al., 2004; Alkuwaity et al., 2012). While responses of these other brain residing cell types have been established, little has been done to determine the impact of the other brain cell types in co-culture with BECs during infection (Figure 1C). Presently, work is being conducted to model the 3-dimentional blood vessel, and presents an opportunity for the incorporation of the natural vessel architecture (Adriani et al., 2015; Cho et al., 2015). These models take advantage of using flow and multicellularity while retaining the overall structure of a blood vessel. It will be of great interest to the field to understand the contribution of these other CNS cell types and architecture, to host-pathogen interaction and overall maintenance of barrier integrity during infection. Establishing multi-cellular in vitro systems that include high barrier forming endothelial cells, such as the iPSC-BECs, will expand our understanding of the host-pathogen interface at brain barriers and CNS infectious disease.

\section{CONCLUSION}

Challenges in modeling host-pathogen interaction at the brain barriers have led to a variety of models both in vitro and in vivo. While in vivo models inherently have interspecies variations, 
widely used in vitro models of BECs generally lack robust BBB-like properties. We believe that an iPSC-derived BEC model may prove useful especially when high barrier function is required, or when a human-specific pathogen is used that lacks good in vivo models.

\section{AUTHOR CONTRIBUTIONS}

All authors listed have made a substantial, direct and intellectual contribution to the work, and approved it for publication.

\section{REFERENCES}

Aaron, P. A., Jamklang, M., Uhrig, J. P., and Gelli, A. (2018). The blood-brain barrier internalises Cryptococcus neoformans via the EphA2-tyrosine kinase receptor. Cell. Microbiol. 20:e12811. doi: 10.1111/cmi.12811

Abbott, N. J., Patabendige, A. A. K., Dolman, D. E. M., Yusof, S. R., and Begley, D. J. (2010). Structure and function of the blood-brain barrier. Neurobiol. Dis. 37, 13-25. doi: 10.1016/j.nbd.2009.07.030

Adriani, G., Ma, D., Pavesi, A., Goh, E. L. K., and Kamm, R. D. (2015). "Modeling the blood-brain barrier in a 3D triple co-culture microfluidic system," in Proceedings of the Annual International Conference of the IEEE Engineering in Medicine and Biology Society, EMBS, Baltimore, MD. doi: 10.1109/EMBC.2015. 7318368

Alimonti, J. B., Ribecco-Lutkiewicz, M., Sodja, C., Jezierski, A., Stanimirovic, D. B., Liu, Q., et al. (2018). Zika virus crosses an in vitro human blood brain barrier model. Fluids Barriers CNS 15:15. doi: 10.1186/s12987-018-0100-y

Alkuwaity, K., Taylor, A., Heckels, J. E., Doran, K. S., and Christodoulides, M. (2012). Group B Streptococcus interactions with human meningeal cells and astrocytes in vitro. PLoS One 7:e42660. doi: 10.1371/journal.pone.0042660

Andrade, E. B., Magalhães, A., Puga, A., Costa, M., Bravo, J., Portugal, C. C., et al. (2018). A mouse model reproducing the pathophysiology of neonatal group B streptococcal infection. Nat. Commun. 9:3138. doi: 10.1038/s41467-01805492-y

Appelt-Menzel, A., Cubukova, A., Günther, K., Edenhofer, F., Piontek, J., Krause, G., et al. (2017). Establishment of a human blood-brain barrier co-culture model mimicking the neurovascular unit using induced pluri- and multipotent stem cells. Stem Cell Rep. 8, 894-906. doi: 10.1016/j.stemcr.2017.02.021

Badger, J. L., Stins, M. F., and Kim, K. S. (1999). Citrobacter freundii invades and replicates in human brain microvascular endothelial cells. Infect. Immun. 67, 4208-4215.

Badger, J. L., Wass, C. A., and Kim, K. S. (2002). Identification of Escherichia coli K1 genes contributing to human brain microvascular endothelial cell invasion by differential fluorescence induction. Mol. Microbiol. 36, 174-182. doi: 10.1046/j. 1365-2958.2000.01840.x

Banerjee, A., van Sorge, N. M., Sheen, T. R., Uchiyama, S., Mitchell, T. J., and Doran, K. S. (2010). Activation of brain endothelium by pneumococcal neuraminidase NanA promotes bacterial internalization. Cell. Microbiol. 12, 1576-1588. doi: 10.1111/j.1462-5822.2010.01490.x

Berardi, A., Rossi, C., Lugli, L., Creti, R., Bacchi Reggiani, M. L., Lanari, M., et al. (2013). Group B Streptococcus late-onset disease: 2003-2010. Pediatrics 131, e361-e368. doi: 10.1542/peds.2012-1231

Bernard, S. C., Simpson, N., Join-Lambert, O., Federici, C., Laran-Chich, M. P., Maïssa, N., et al. (2014). Pathogenic Neisseria meningitidis utilizes CD147 for vascular colonization. Nat. Med. 20, 725-731. doi: 10.1038/nm.3563

Blanot, S., Joly, M. M., Vilde, F., Jaubert, F., Clement, O., Frija, G., et al. (1997). A gerbil model for rhombencephalitis due to Listeria monocytogenes. Microb. Pathog. 23, 39-48. doi: 10.1006/mpat.1997.0131

Canfield, S. G., Stebbins, M. J., Morales, B. S., Asai, S. W., Vatine, G. D., Svendsen, C. N., et al. (2017). An isogenic blood-brain barrier model comprising brain endothelial cells, astrocytes, and neurons derived from human induced pluripotent stem cells. J. Neurochem. 140, 874-888. doi: 10.1111/jnc.13923

Cecchelli, R., Aday, S., Sevin, E., Almeida, C., Culot, M., Dehouck, L., et al. (2014). A stable and reproducible human blood-brain barrier model derived

\section{FUNDING}

This work was supported by the NIH grants NS103844 to ES and NS051247 to KD. BK was supported by a postdoctoral fellowship from the Alexander von Humboldt Foundation.

\section{ACKNOWLEDGMENTS}

We thank Elizabeth Rossi for providing the artwork and graphics of Figure 1.

from hematopoietic stem cells. PLoS One 9:e99733. doi: 10.1371/journal.pone. 0099733

Chiavolini, D., Pozzi, G., and Ricci, S. (2008). Animal models of Streptococcus pneumoniae disease. Clin. Microbiol. Rev. 21, 666-685. doi: 10.1128/CMR. 00012-08

Cho, H., Seo, J. H., Wong, K. H. K., Terasaki, Y., Park, J., Bong, K., et al. (2015). Three-dimensional blood-brain barrier model for in vitro studies of neurovascular pathology. Sci. Rep. 5:15222. doi: 10.1038/srep15222

Clark, P. A., Al-Ahmad, A. J., Qian, T., Zhang, R. R., Wilson, H. K., Weichert, J. P., et al. (2016). Analysis of cancer-targeting alkylphosphocholine analogue permeability characteristics using a human induced pluripotent stem cell blood-brain barrier model. Mol. Pharm. 13, 3341-3349. doi: 10.1021/acs. molpharmaceut.6b00441

Cooley, I. D., Chauhan, V. S., Donneyz, M. A., and Marriott, I. (2014). Astrocytes produce IL-19 in response to bacterial challenge and are sensitive to the immunosuppressive effects of this IL-10 family member. Glia $62,818-828$. doi: 10.1002/glia.22644

Coureuil, M., Lécuyer, H., Bourdoulous, S., and Nassif, X. (2017). A journey into the brain: insight into how bacterial pathogens cross blood-brain barriers. Nat. Rev. Microbiol. 15, 149-159. doi: 10.1038/nrmicro.2016.178

Coureuil, M., Lécuyer, H., Scott, M. G. H., Boularan, C., Enslen, H., Soyer, M., et al. (2010). Meningococcus hijacks a $\beta 2$-adrenoceptor/ $\beta$-arrestin pathway to cross brain microvasculature endothelium. Cell 143, 1149-1160. doi: 10.1016/j.cell. 2010.11.035

Delannoy, C. M. J., Crumlish, M., Fontaine, M. C., Pollock, J., Foster, G., Dagleish, M. P., et al. (2013). Human Streptococcus agalactiae strains in aquatic mammals and fish. BMC Microbiol. 13:41. doi: 10.1186/1471-2180-13-41

Deng, L., Mu, R., Weston, T. A., Spencer, B. L., Liles, R. P., and Doran, K. S. (2018). Characterization of a two-component system transcriptional regulator, LtdR, that impacts group B streptococcal colonization and disease. Infect. Immun. 86:e00822-17. doi: 10.1128/iai.00822-17

Doran, K. S., Engelson, E. J., Khosravi, A., Maisey, H. C., Fedtke, I., Equils, O., et al. (2005). Blood-brain barrier invasion by group B Streptococcus depends upon proper cell-surface anchoring of lipoteichoic acid. J. Clin. Invest. 115, 2499-2507. doi: 10.1172/JCI23829

Doran, K. S., Fulde, M., Gratz, N., Kim, B. J., Nau, R., Prasadarao, N., et al. (2016). Host-pathogen interactions in bacterial meningitis. Acta Neuropathol. 131, 185-209. doi: 10.1007/s00401-015-1531-z

Doran, K. S., and Nizet, V. (2004). Molecular pathogenesis of neonatal group B streptococcal infection: no longer in its infancy. Mol. Microbiol. 54, 23-31. doi: 10.1111/j.1365-2958.2004.04266.x

D'Orazio, S. E. F. (2014). Animal models for oral transmission of Listeria monocytogenes. Front. Cell. Infect. Microbiol. 4:15. doi: 10.3389/fcimb.2014. 00015

Eigenmann, D. E., Xue, G., Kim, K. S., Moses, A. V., Hamburger, M., and Oufir, M. (2013). Comparative study of four immortalized human brain capillary endothelial cell lines, hCMEC/D3, hBMEC, TY10, and BB19, and optimization of culture conditions, for an in vitro blood-brain barrier model for drug permeability studies. Fluids Barriers CNS 10:33. doi: 10.1186/20458118-10-33

Engelhardt, B., and Sorokin, L. (2009). The blood-brain and the bloodcerebrospinal fluid barriers: function and dysfunction. Semin. Immunopathol. 31, 497-511. doi: 10.1007/s00281-009-0177-0 
Feikin, D. R., Kagucia, E. W., Loo, J. D., Link-Gelles, R., Puhan, M. A., Cherian, T., et al. (2013). Serotype-specific changes in invasive pneumococcal disease after pneumococcal conjugate vaccine introduction: a pooled analysis of multiple surveillance sites. PLoS Med. 10:e1001517. doi: 10.1371/journal.pmed.1001517

Ferrieri, P., Burke, B., and Nelson, J. (1980). Production of bacteremia and meningitis in infant rats with group B streptococcal serotypes. Infect. Immun. 27, 1023-1032.

Fowler, M. I., Weller, R. O., Heckels, J. E., and Christodoulides, M. (2004). Different meningitis-causing bacteria induce distinct inflammatory responses on interaction with cells of the human meninges. Cell. Microbiol. 6, 555-567. doi: 10.1111/j.1462-5822.2004.00382.x

Gomes, S. F. M., Westermann, A. J., Sauerwein, T., Hertlein, T., Förstner, K. U., Ohlsen, K., et al. (2019). Induced pluripotent stem cell-derived brain endothelial cells as a cellular model to study Neisseria meningitidis infection. Front. Microbiol. 10:1181. doi: 10.3389/fmicb.2019.01181

Grandgirard, D., Steiner, O., Täuber, M. G., and Leib, S. L. (2007). An infant mouse model of brain damage in pneumococcal meningitis. Acta Neuropathol. 114, 609-617. doi: 10.1007/s00401-007-0304-8

Greiffenberg, L., Goebel, W., Kim, K. S., Weiglein, I., Bubert, A., Engelbrecht, F., et al. (1998). Interaction of Listeria monocytogenes with human brain microvascular endothelial cells: inlB-dependent invasion, long-term intracellular growth, and spread from macrophages to endothelial cells. Infect. Immun. 66, 5260-5267.

Harvie, E. A., Green, J. M., Neely, M. N., and Huttenlocher, A. (2013). Innate immune response to Streptococcus iniae infection in zebrafish larvae. Infect. Immun. 81, 110-121. doi: 10.1128/IAI.00642-12

Helms, H. C., Abbott, N. J., Burek, M., Cecchelli, R., Couraud, P. O., Deli, M. A., et al. (2015). In vitro models of the blood-brain barrier: an overview of commonly used brain endothelial cell culture models and guidelines for their use. J. Cereb. Blood Flow Metab. 36, 862-890. doi: 10.1177/0271678X16630991

Hoffman, J. A., Badger, J. L., Zhang, Y., Huang, S. H., and Kim, K. S. (2000). Escherichia coli $\mathrm{K} 1$ aslA contributes to invasion of brain microvascular endothelial cells in vitro and in vivo. Infect. Immun. 68, 5062-5067. doi: 10. 1128/IAI.68.9.5062-5067.2000

Hollmann, E. K., Bailey, A. K., Potharazu, A. V., Neely, M. D., Bowman, A. B., and Lippmann, E. S. (2017). Accelerated differentiation of human induced pluripotent stem cells to blood-brain barrier endothelial cells. Fluids Barriers CNS 14:9. doi: 10.1186/s12987-017-0059-0

Jim, K. K., Engelen-Lee, J. Y., van der Sar, A. M., Bitter, W., Brouwer, M. C., van der Ende, A., et al. (2016). Infection of zebrafish embryos with live fluorescent Streptococcus pneumoniae as a real-time pneumococcal meningitis model. J. Neuroinflammation 13:188. doi: 10.1186/s12974-016-0655-y

Jiménez-Munguía, I., Pulzova, L., Kanova, E., Tomeckova, Z., Majerova, P., Bhide, K., et al. (2018). Proteomic and bioinformatic pipeline to screen the ligands of S. pneumoniae interacting with human brain microvascular endothelial cells. Sci. Rep. 8:5231. doi: 10.1038/s41598-018-23485-1

Johswich, K. O., McCaw, S. E., Islam, E., Sintsova, A., Gu, A., Shively, J. E., et al. (2013). In vivo adaptation and persistence of Neisseria meningitidis within the nasopharyngeal mucosa. PLoS Pathog. 9:e1003509. doi: 10.1371/journal.ppat. 1003509

Kaufmann, A. F., and Quist, K. D. (1969). Pneumococcal meningitis and peritonitis in rhesus monkeys. J. Am. Vet. Med. Assoc. 155, 1158-1162.

Kim, B. J., Bee, O. B., McDonagh, M. A., Stebbins, M. J., Palecek, S. P., Doran, K. S., et al. (2017). Modeling group B Streptococcus and blood-brain barrier interaction by using induced pluripotent stem cell-derived brain endothelial cells. mSphere 2:e00398-17. doi: 10.1128/mSphere.00398-17

Kim, B. J., Hancock, B. M., Bermudez, A., Cid, N., Del Reyes, E., Van Sorge, N. M., et al. (2015a). Bacterial induction of Snaill contributes to blood-brain barrier disruption. J. Clin. Invest. 125, 2473-2483. doi: 10.1172/JCI74159

Kim, B. J., Hancock, B. M., Del Cid, N., Bermudez, A., Traver, D., and Doran, K. S. (2015b). Streptococcus agalactiae infection in zebrafish larvae. Microb. Pathog. 79, 57-60. doi: 10.1016/j.micpath.2015.01.007

Kim, K. S., Itabashi, H., Gemski, P., Sadoff, J., Warren, R. L., and Cross, A. S. (1992). The K1 capsule is the critical determinant in the development of Escherichia coli meningitis in the rat. J. Clin. Invest. 90, 897-905. doi: 10.1172/ JCI115965

Koedel, U., Paul, R., Winkler, F., Kastenbauer, S., Huang, P. L., and Pfister, H. W. (2001). Lack of endothelial nitric oxide synthase aggravates murine pneumococcal meningitis. J. Neuropathol. Exp. Neurol. 60, 1041-1050. doi: $10.1093 /$ jnen/60.11.1041

Kokubu, Y., Yamaguchi, T., and Kawabata, K. (2017). In vitro model of cerebral ischemia by using brain microvascular endothelial cells derived from human induced pluripotent stem cells. Biochem. Biophys. Res. Commun. 486, 577-583. doi: 10.1016/j.bbrc.2017.03.092

Koopmans, M. M., Engelen-Lee, J. Y., Brouwer, M. C., Jaspers, V., Man, W. K., Vall Seron, M., et al. (2018). Characterization of a Listeria monocytogenes meningitis mouse model. J. Neuroinflammation 15:257. doi: 10.1186/s12974-018-1293-3

Lecuit, M., Vandormael-Pournin, S., Lefort, J., Huerre, M., Gounon, P., Dupuy, C., et al. (2001). A transgenic model for listeriosis: role of internalin in crossing the intestinal barrier. Science 292, 1722-1725. doi: 10.1126/science.1059852

Lemoy, M. J. M., Lopes, D. A., Reader, J. R., Westworth, D. R., and Tarara, R. P. (2012). Meningoencephalitis due to Listeria monocytogenes in a pregnant rhesus macaque (Macaca mulatta). Comp. Med. 62, 443-447.

Lim, R. G., Quan, C., Reyes-Ortiz, A. M., Lutz, S. E., Kedaigle, A. J., Gipson, T. A., et al. (2017). Huntington's disease iPSC-derived brain microvascular endothelial cells reveal WNT-mediated angiogenic and blood-brain barrier deficits. Cell Rep. 19, 1365-1377. doi: 10.1016/j.celrep.2017.04.021

Lippmann, E. S., Al-Ahmad, A., Azarin, S. M., Palecek, S. P., and Shusta, E. V. (2014). A retinoic acid-enhanced, multicellular human blood-brain barrier model derived from stem cell sources. Sci. Rep. 4:4160. doi: 10.1038/srep04160

Lippmann, E. S., Al-Ahmad, A., Palecek, S. P., and Shusta, E. V. (2013). Modeling the blood-brain barrier using stem cell sources. Fluids Barriers CNS 10:2. doi: 10.1186/2045-8118-10-2

Lippmann, E. S., Azarin, S. M., Kay, J. E., Nessler, R. A., Wilson, H. K., Al-Ahmad, A., et al. (2012). Derivation of blood-brain barrier endothelial cells from human pluripotent stem cells. Nat. Biotechnol. 30, 783-791. doi: 10.1038/nbt.2247

Liu, G. Y., Doran, K. S., Lawrence, T., Turkson, N., Puliti, M., Tissi, L., et al. (2004). Sword and shield: linked group B streptococcal beta-hemolysin/cytolysin and carotenoid pigment function to subvert host phagocyte defense. Proc. Natl. Acad. Sci. U.S.A. 101, 14491-14496. doi: 10.1073/pnas.0406143101

Mackinnon, F. G., Gorringe, A. R., Funnell, S. G. P., and Robinson, A. (1992). Intranasal infection of infant mice with Neisseria meningitidis. Microb. Pathog. 12, 415-420. doi: 10.1016/0882-4010(92)90004-8

Marra, A., and Brigham, D. (2001). Streptococcus pneumoniae causes experimental meningitis following intranasal and otitis media infections via a nonhematogenous route. Infect. Immun. 69, 7318-7325. doi: 10.1128/IAI.69.12.7318-7325.2001

Maury, M. M., Tsai, Y. H., Charlier, C., Touchon, M., Chenal-Francisque, V., Leclercq, A., et al. (2016). Uncovering Listeria monocytogenes hypervirulence by harnessing its biodiversity. Nat. Genet. 48, 308-313. doi: 10.1038/ng.3501

Michael Scheld, W., Fletcher, D. D., Fink, F. N., and Sande, M. A. (1979). Response to therapy in an experimental rabbit model of meningitis due to Listeria monocytogenes. J. Infect. Dis. 140, 287-294. doi: 10.1093/infdis/140.3.287

Miraglia, M. C., Rodriguez, A. M., Barrionuevo, P., Rodriguez, J., Kim, K. S., Dennis, V. A., et al. (2018). Brucella abortus traverses brain microvascular endothelial cells using infected monocytes as a trojan horse. Front. Cell. Infect. Microbiol. 8:200. doi: 10.3389/fcimb.2018.00200

Mishra, A., Nam, G. H., Gim, J. A., Lee, H. E., Jo, A., and Kim, H. S. (2018). Current challenges of Streptococcus infection and effective molecular, cellular, and environmental control methods in aquaculture. Mol. Cells 41, 495-505. doi: 10.14348/molcells.2018.2154

Mittal, R., Gonzalez-Gomez, I., Panigrahy, A., Goth, K., Bonnet, R., and Prasadarao, N. V. (2010). IL-10 administration reduces PGE-2 levels and promotes CR3-mediated clearance of Escherichia coli K1 by phagocytes in meningitis. J. Exp. Med. 207, 1307-1319. doi: 10.1084/jem.20092265

Mittal, R., Krishnan, S., Gonzalez-gomez, I., and Prasadarao, N. V. (2011). Deciphering the roles of outer membrane protein A extracellular loops in the pathogenesis of Escherichia coli K1. J. Biol. Chem. 286, 2183-2193. doi: 10.1074/ jbc.M110.178236

Mook-kanamori, B. B., Geldhoff, M., van der Poll, T., and van de Beek, D. (2011). Pathogenesis and pathophysiology of pneumococcal meningitis. Clin. Microbiol. Rev. 24, 557-591. doi: 10.1128/cmr.00008-11

Mutso, M., Saul, S., Rausalu, K., Susova, O., Žusinaite, E., Mahalingam, S., et al. (2017). Reverse genetic system, genetically stable reporter viruses and packaged subgenomic replicon based on a Brazilian zika virus isolate. J. Gen. Virol. 98, 2712-2724. doi: 10.1099/jgv.0.000938 
N’Dilimabaka, N., Taoufiq, Z., Zougbédé, S., Bonnefoy, S., Lorthiois, A., Couraud, P. O., et al. (2014). P. falciparum isolate-specific distinct patterns of induced apoptosis in pulmonary and brain endothelial cells. PLoS One 9:e90692. doi: 10.1371/journal.pone.0090692

Nitta, T., Hata, M., Gotoh, S., Seo, Y., Sasaki, H., Hashimoto, N., et al. (2003). Size-selective loosening of the blood-brain barrier in claudin5-deficient mice. J. Cell Biol. 161, 653-660. doi: 10.1083/jcb.20030 2070

Nizet, V., Kim, K. S., Stins, M., Jonas, M., Chi, E. Y., Nguyen, D., et al. (1997). Invasion of brain microvascular endothelial cells by group B streptococci. Infect. Immun. 65, 5074-5081.

O’Brown, N. M., Pfau, S. J., and Gu, C. (2018). Bridging barriers: a comparative look at the blood-brain barrier across organisms. Genes Dev. 32, 466-478. doi: 10.1101/gad.309823.117

Patterson, H., Saralahti, A., Parikka, M., Dramsi, S., Trieu-Cuot, P., Poyart, C., et al. (2012). Adult zebrafish model of bacterial meningitis in Streptococcus agalactiae infection. Dev. Comp. Immunol. 38, 447-455. doi: 10.1016/j.dci.2012. 07.007

Qian, T., Maguire, S. E., Canfield, S. G., Bao, X., Olson, W. R., Shusta, E. V., et al. (2017). Directed differentiation of human pluripotent stem cells to blood-brain barrier endothelial cells. Sci. Adv. 3:e1701679. doi: 10.1126/sciadv. 1701679

Rahman, N. A., Rasil, A. N. H. M., Meyding-Lamade, U., Craemer, E. M., Diah, S., Tuah, A. A., et al. (2016). Immortalized endothelial cell lines for in vitro blood-brain barrier models: a systematic review. Brain Res. 1642, 532-545. doi: 10.1016/j.brainres.2016.04.024

Redzic, Z. (2011). Molecular biology of the blood-brain and the bloodcerebrospinal fluid barriers: similarities and differences. Fluids Barriers CNS 8:3. doi: $10.1186 / 2045-8118-8-3$

Reiß, A., Braun, J. S., Jäger, K., Freyer, D., Laube, G., Bührer, C., et al. (2011). Bacterial pore-forming cytolysins induce neuronal damage in a rat model of neonatal meningitis. J. Infect. Dis. 203, 393-400. doi: 10.1093/infdis/ jiq047

Rua, R., and McGavern, D. B. (2018). Advances in meningeal immunity. Trends Mol. Med. 24, 542-559. doi: 10.1016/j.molmed.2018.04.003

Scanga, C. A., and Flynn, J. L. (2014). Modeling tuberculosis in nonhuman primates. Cold Spring Harb. Perspect. Med. 4:a018564. doi: 10.1101/cshperspect. a018564

Schubert-Unkmeir, A. (2017). Molecular mechanisms involved in the interaction of Neisseria meningitidis with cells of the human blood-cerebrospinal fluid barrier. Pathog. Dis. 75:ftx023. doi: 10.1093/femspd/ftx023

Seele, J., Nau, R., Prajeeth, C., Stangel, M., Valentin-Weigand, P., and Seitz, M. (2016). Astrocytes enhance Streptococcus suis-glial cell interaction in primary astrocyte-microglial cell co-cultures. Pathogens 5:E43. doi: 10.3390/ pathogens5020043

Shapiro, M. A., Donovan, K. D., and Gage, J. W. (2000). Comparative therapeutic efficacy of clinafloxacin in a pneumococcal meningitis mouse model. J. Antimicrob. Chemother. 45, 489-492. doi: 10.1093/jac/45. 4.489

Shenep, J. L., and Mogan, K. A. (1984). Kinetics of endotoxin release during antibiotic therapy for experimental gram-negative bacterial sepsis. J. Infect. Dis. 150, 380-388. doi: 10.1093/infdis/150.3.380

Sinai, R. E., Marks, M. I., Powell, K. R., and Pai, C. H. (1980). Model of neonatal meningitis caused by Escherichia coli K1 in guinea pigs. J. Infect. Dis. 141, 193-197. doi: 10.1093/infdis/141.2.193

Spindler, K. R., and Hsu, T. H. (2012). Viral disruption of the bloodbrain barrier. Trends Microbiol. 20, 282-290. doi: 10.1016/j.tim.2012. 03.009

Stebbins, M. J., Wilson, H. K., Canfield, S. G., Qian, T., Palecek, S. P., and Shusta, E. V. (2016). Differentiation and characterization of human pluripotent stem cell-derived brain microvascular endothelial cells. Methods 101, 93-102. doi: 10.1016/j.ymeth.2015.10.016

Stins, M. F., Badger, J., and Sik Kim, K. (2001). Bacterial invasion and transcytosis in transfected human brain microvascular endothelial cells. Microb. Pathog. 30, 19-28. doi: 10.1006/mpat.2000.0406

Stoner, T. D., Weston, T. A., Trejo, J., and Doran, K. S. (2015). Group B streptococcal infection and activation of human astrocytes. PLoS One 10:e0128431. doi: 10.1371/journal.pone.0128431
Sulc, P., Hengstler, B., Krinke, G., O’Reilly, T., and Zak, O. (1992). Experimental rabbit model of meningitis produced by Haemophilus influenzae serotype c. J. Med. Microbiol. 36, 312-317.doi: 10.1099/00222615-365-312

Syvänen, S., Lindhe, Ö., Palner, M., Kornum, B. R., Rahman, O., Långström, B., et al. (2009). Species differences in blood-brain barrier transport of three positron emission tomography radioligands with emphasis on P-glycoprotein transport. Drug Metab. Dispos 37, 635-643. doi: 10.1124/dmd.108.024745

Tan, T. Q., Smith, C. W., Hawkins, E. P., Mason, E. O., and Kaplan, S. L. (1995). Hematogenous bacterial meningitis in an intercellular adhesion molecule-1deficient infant mouse model. J. Infect. Dis. 171, 342-349. doi: 10.1093/infdis/ 171.2.342

Tauber, M. G. (1998). Rabbit model of bacterial meningitis. Clin. Microbiol. Infect. 4, 557-559. doi: 10.1111/j.1469-0691.1998.tb00036.x

Tucker, E. W., Pokkali, S., Zhang, Z., DeMarco, V. P., Klunk, M., Smith, E. S., et al. (2016). Microglia activation in a pediatric rabbit model of tuberculous meningitis. Dis. Model. Mech. 9, 1497-1506. doi: 10.1242/dmm.027326

Uchiyama, S., Carlin, A. F., Khosravi, A., Weiman, S., Banerjee, A., Quach, D., et al. (2009). The surface-anchored NanA protein promotes pneumococcal brain endothelial cell invasion. J. Exp. Med. 206, 1845-1852. doi: 10.1084/jem. 20090386

van Leeuwen, L. M., van der Kuip, M., Youssef, S. A., de Bruin, A., Bitter, W., van Furth, A. M., et al. (2014). Modeling tuberculous meningitis in zebrafish using Mycobacterium marinum. Dis. Model. Mech. 7, 1111-1122. doi: 10.1242/dmm. 015453

Vatine, G. D., Al-Ahmad, A., Barriga, B. K., Svendsen, S., Salim, A., Garcia, L., et al. (2016). Modeling psychomotor retardation using iPSCs from MCT8-deficient patients indicates a prominent role for the blood-brain barrier. Cell Stem Cell 20, 831-843.e5. doi: 10.1016/j.stem.2017.04.002

Volle, R., Archimbaud, C., Couraud, P. O., Romero, I. A., Weksler, B., Mirand, A., et al. (2015). Differential permissivity of human cerebrovascular endothelial cells to enterovirus infection and specificities of serotype EV-A71 in crossing an in vitro model of the human blood-brain barrier. J. Gen. Virol. 96(Pt 7), 1682-1695. doi: 10.1099/vir.0.000103

Wang, J., Kong, D., Zhang, S., Jiang, H., Zheng, Y., Zang, Y., et al. (2015). Interaction of fibrinogen and muramidase-released protein promotes the development of Streptococcus suis meningitis. Front. Microbiol. 6:1001. doi: 10.3389/fmicb.2015.01001

Wang, R., Li, L., Huang, Y., Huang, T., Tang, J., Xie, T., et al. (2017). Pathogenicity of human ST23 Streptococcus agalactiae to fish and genomic comparison of pathogenic and non-pathogenic isolates. Front. Microbiol. 8:1938. doi: 10.3389/ fmicb.2017.01938

Wang, Y., and Kim, K. S. (2002). Role of OmpA and IbeB in Escherichia coli K1 invasion of brain microvascular endothelial cells in vitro and in vivo. Pediatr. Res. 51, 559-563. doi: 10.1203/00006450-200205000-00003

Warren, M. S., Zerangue, N., Woodford, K., Roberts, L. M., Tate, E. H., Feng, B., et al. (2009). Comparative gene expression profiles of $A B C$ transporters in brain microvessel endothelial cells and brain in five species including human. Pharmacol. Res. 59, 404-413. doi: 10.1016/j.phrs.2009.02.00

Weksler, B. B. (2005). Blood-brain barrier-specific properties of a human adult brain endothelial cell line. FASEB J. 19, 1872-1874. doi: 10.1096/fj.04-3458fje

Weksler, B. B., Subileau, E. A., Perrière, N., Charneau, P., Holloway, K., Leveque, M., et al. (2005). Blood-brain barrier-specific properties of a human adult brain endothelial cell line. FASEB J. 19, 1872-1874. doi: 10.1096/fj.04-3458fje

Wong, A. D., Ye, M., Levy, A. F., Rothstein, J. D., Bergles, D. E., and Searson, P. C. (2013). The blood-brain barrier: an engineering perspective. Front. Neuroeng. 6:7. doi: 10.3389/fneng.2013.00007

Yang, R., Liu, W., Miao, L., Yang, X., Fu, J., Dou, B., et al. (2016). Induction of VEGFA and Snail-1 by meningitic Escherichia coli mediates disruption of the blood-brain barrier. Oncotarget 7, 63839-63855. doi: 10.18632/oncotarget. 11696

Yi, K., Stephens, D. S., and Stojiljkovic, I. (2003). Development and evaluation of an improved mouse model of meningococcal colonization. Infect. Immun. 71, 1849-1855. doi: 10.1128/IAI.71.4.1849-1855.2003

Zarantonelli, M. L., Szatanik, M., Giorgini, D., Hong, E., Huerre, M., Guillou, F., et al. (2007). Transgenic mice expressing human transferrin as a model for meningococcal infection. Infect. Immun. 75, 5609-5614. doi: 10.1128/IAI. 00781-07 
Zlokovic, B. V. (2005). Neurovascular mechanisms of Alzheimer's neurodegeneration. Trends Neurosci. 28, 202-208. doi: 10.1016/j.tins.2005.02.001

Zwijnenburg, P. J. G., van der Poll, T., Florquin, S., van Deventer, S. J. H., Roord, J. J., and van Furth, A. M. (2001). Experimental pneumococcal meningitis in mice: a model of intranasal infection. J. Infect. Dis. 183, 1143-1146. doi: $10.1086 / 319271$

Zysk, G., Brück, W., Gerber, J., Brück, Y., Prange, H. W., and Nau, R. (1996). Antiinflammatory treatment influences neuronal apoptotic cell death in the dentate gyrus in experimental pneumococcal meningitis. J. Neuropathol. Exp. Neurol. 55, 722-728. doi: 10.1097/00005072-199606000-0000
Conflict of Interest Statement: The authors declare that the research was conducted in the absence of any commercial or financial relationships that could be construed as a potential conflict of interest.

Copyright (c) $2019 \mathrm{Kim}$, Shusta and Doran. This is an open-access article distributed under the terms of the Creative Commons Attribution License (CC BY). The use, distribution or reproduction in other forums is permitted, provided the original author(s) and the copyright owner(s) are credited and that the original publication in this journal is cited, in accordance with accepted academic practice. No use, distribution or reproduction is permitted which does not comply with these terms. 